\title{
Prediction of unsuccessful endometrial ablation: a retrospective study
}

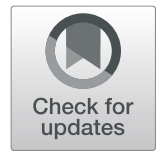

K. Y. R. Stevens ${ }^{1,2^{*}}$ D, D. Meulenbroeks ${ }^{1}$, S. Houterman ${ }^{3}$, T. Gijsen ${ }^{4}$, S. Weyers ${ }^{2}$ and B. C. Schoot ${ }^{1,2}$

\begin{abstract}
Background: Endometrial ablation (EA) is a frequently used treatment for abnormal uterine bleeding, mainly due to the low risks, low costs and short recovery time associated with the procedure. On the short term, it seems successful, long-term follow-up however, shows decreasing patient satisfaction as well as treament efficacy. There even is a postablation hysterectomy rate up to $21 \%$. Multiple factors seem to' influence the outcome of EA. Due to dissimilarities in and variety of these factors, it has not been possible so far to predict the success rate of EA based on pre-operative factors. Therefore, the aim of this study is to develop two prediction models to help counsel patients for failure of EA or necessity of surgical re-intervention within 2 years after EA.

Methods: We designed a retrospective two-centred cohort study in Catharina Hospital, Eindhoven and Elkerliek Hospital, Helmond, both non-university teaching hospitals in the Netherlands. The study population consisted of 446 pre-menopausal women who underwent EA for abnormal uterine bleeding, with a minimum follow-up time of 2 years. Multivariate logistic regression analysis was used to create the prediction models.

Results: The mean age of the patients was 43.8 years (range 20-55), 97.3\% had complaints of menorrhagia, $57.4 \%$ of dysmenorrhoea and $61.0 \%$ had complaints of intermittent or irregular bleeding. $18.8 \%$ of patients still needed a hysterectomy after EA. The risk of re-intervention was significantly greater in women with menstrual duration $>7$ days or a previous caesarean section, while pre-operative menorrhagia was significantly associated with success of EA. Younger age, parity $\geq 5$ and dysmenorrhea were significant multivariate predictors in both models. These predictors were used to develop prediction models, which had a C-index of 0.71 and 0.68 respectively.

Conclusion: We propose two multivariate models to predict the chance of failure and surgical re-intervention within 2 years after EA. Due to the permanent character of EA, the increasing number of post-operative failure and re-interventions, these prediction models could be useful for both the doctor and patient and may contribute to the shared decision-making.
\end{abstract}

Keywords: Prediction model, Endometrial ablation, Abnormal uterine bleeding, Patient counselling.

\section{Article}

The use of EA as treatment for abnormal uterine bleeding is rapidly increasing. This surgical outpatient procedure offers a minimally invasive alternative for hysterectomy in case non-surgical treatment is not effective. The success of EA is

\footnotetext{
* Correspondence: Kyr.stevens@gmail.com

Partly presented as abstract at:- The 24th Annual International Congress of the European Society of Gynaecological Endoscopy, Budapest Hungary 2015- The 26th Annual International Congress of the European Society of Gynaecological Endoscopy, Antalya Turkey 2017- The 46th global congress of the American Association of Gynaecologic Laparoscopists, Washington D.C. United States 2017 ${ }^{1}$ Department of Obstetrics and Gynaecology, Catharina Hospital, Michelangelolaan 2, 5623 Eindhoven, EJ, The Netherlands

2Women's Clinic, Ghent University Hospital, Comeel Heymanslaan 10, 9000 Ghent, Belgium Full list of author information is available at the end of the article
}

mainly based on the short recovery time, low risks and low costs associated with the procedure. [1-5] In contrast to the short-term success, long-term follow-up shows decreasing patient satisfaction as well as treatment efficacy [6-13]. A common complaint of patients after EA is pain (20-23\%), which often leads to re-interventions [7, 8]. Besides the occurrence, persistence or aggravation of pain, another reason for re-intervention can be persisting bleeding disturbances $[7,10]$. Retrospective cohort data reveal a post-ablation hysterectomy rate up to $21 \%[6,8-10,12,14-16]$.

Several factors influencing failure of EA have been reported. It has been shown that the probability of success increases with older age at the time of 
intervention. [6, 8-12, 14, 17, 18] Prior studies demonstrated different negative influencing factors, such as the duration of pre-operative menstruation, dysmenorrhea, the position of the uterus and the thickness of the endometrium $[6,7,9-13,15,19,20]$.

However, due to dissimilarities in and variety of the factors previously described, it has not been possible so far to predict the success rate of EA based on pre-operative factors. Patient counselling is therefore difficult.

The aim of this study was to develop two prediction models to counsel patients for failure of EA and for surgical re-intervention within 2 years. In addition, we established the hysterectomy rate, the additional treatment rate and the patient satisfaction after EA.

\section{Methods}

This retrospective two-centred cohort study included patients with EA for complaints of abnormal uterine bleeding in two non-university teaching hospitals in the Netherlands (the Catharina Hospital in Eindhoven and the Elkerliek Hospital in Helmond). In both hospitals, similar ablation techniques were used between 2004 and 2013, namely Cavatherm ${ }^{\circ}$ (Veldana Medical SA, Morges, Switzerland), Thermablate ${ }^{\circ}$ EAS (Idoman, Ireland) and Gynecare Thermachoice ${ }^{\circ}$ (Ethicon, Sommerville, US). Previous research showed that these techniques were equal in effectivity $[13,21]$. The study was approved by the local medical ethical review board. All patients gave informed consent.

\section{Patients}

Patients were identified in the Electronic Patient Care System using the following search terms: endometrial ablation, balloon-coagulation endometrium, coagulation uterus and endoresection: hysteroscopic extensive. The retrieved cases were verified by means of chart review.

Patients were excluded if they were post-menopausal at the time of treatment, if they had or were suspected of having an endometrial malignancy or if they had uterine cavity deformations (anomalies, fibroids, adenomyosis or a polyp).

Follow-up period after EA was at least 2 years, since earlier research showed that most re-interventions took place in this post-operative 2-year period [8, 15, 20-24]. Follow-up ended on the day of hysterectomy, in case of death or on April 15, 2015.

\section{Data extraction}

Two researchers extracted all the data from individual patient files. Patients were requested to complete a questionnaire concerning follow-up information. In case of non-response, patients were contacted by letter again and ultimately by telephone. The questionnaire comprised questions based on significant factors previously published [6, 9-15, 17-20]. Charts and patient responses were used to obtain post-procedural information on menstrual pattern, patient satisfaction, additional treatment and pathology results in case a hysterectomy was performed.

Abnormal blood loss as procedure outcome was defined by a combination of intermittent or irregular bleeding and heavy menstrual bleeding (HMB) following EA. Treatment prior to EA was defined as any treatment for abnormal uterine bleeding performed prior to surgery. Satisfaction was evaluated on a four-point scale (1: very satisfied, 2: satisfied, 3: dissatisfied, 4: very dissatisfied). During analysis, we combined the answers scoring 1 and 2 points as 'satisfied' and those scoring 3 and 4 points as 'dissatisfied'.

\section{Outcomes}

The primary aim of this study was to identify significant predictors of failure of EA and surgical re-intervention within 2 years after EA by constructing a prediction model for each outcome. Failure was defined as pelvic pain, abnormal blood loss or dissatisfaction after the procedure. Secondary outcomes of this study were hysterectomy rate, patient satisfaction and percentage of additional treatment after EA, for example hormonal treatment, re-ablation or endometrial resection.

\section{Statistical analysis}

Statistical analysis was performed using the statistical package IBM SPSS statistics, software version 21.0 (IBM Corp., Armonk, NY, USA). Continuous variables were presented as mean and standard deviation or median and minimum-maximum, depending on normality. Categorical variables were reported as frequencies.

Univariable logistic regression analysis was used to determine which predictive factors were significant. Corresponding odds ratios (OR) and 95\% confidence intervals (CI) were given.

Predictive factors with a $p$ value $<.10$ were used in the multivariable analysis. A manual selection process was done by progressively excluding the variable with the highest $p$ value.

The $p$ value of 0.10 was chosen because, as Steyerberg et al. stated, an incorrect exclusion of a variable would be far more detrimental than considering to put in a factor too many $[25,26]$.

Possible interaction between the significant predictors in the model was tested using interaction terms. Furthermore, multicollinearity was tested. 
The overall fit of the model was tested using the C-index (area under the curve). A value of 1.0 for the C-index implies a perfectly produced model, where every prediction made with the variables in the model is true. However, a value of 0.5 implies that the model gives information that is equal to that given by the probability on its own. Values over 0.7 indicate a good model, whereas values over 0.8 indicate a strong model [27, 28].

The regression model was internally validated with bootstrap resampling $(n=5000)$ [29-33]. Regression coefficients of the model were multiplied by the shrinkage factor to correct for over-optimism of the original model.

\section{Results}

In this study, 762 patients were identified. After examination of patient records, 33 patients were excluded; 30 patients did not completely fulfil the inclusion criteria (e.g. malignancy, cavity deformations) and 3 patients had an incomplete ablation procedure.

The remaining 729 participants were contacted, of whom 283 did not respond despite our best efforts. This resulted in 446 included patients, which represents a response rate of $61 \%$ (Fig. 1).

The baseline patient characteristics are listed in Table 1. The mean age of the patients at the time of EA was 43.8 years ( $\mathrm{SD} \pm 5.5$, range $20-55$ ). The mean BMI was $26.5 \mathrm{~kg} / \mathrm{m}^{2}(\mathrm{SD} \pm 4.7)$. A mean number of parity of $2.2(\mathrm{SD} \pm 1.0)$ was observed; $13.7 \%$ of the women had undergone a previous caesarean section.

Menorrhagia was present in $97.3 \%$ of patients, $61 \%$ had complaints of intermittent or irregular bleeding and $57.4 \%$ had complaints of dysmenorrhea. In $39.4 \%$ of patients, the duration of the menstruation was longer than 7 days (Table 1).

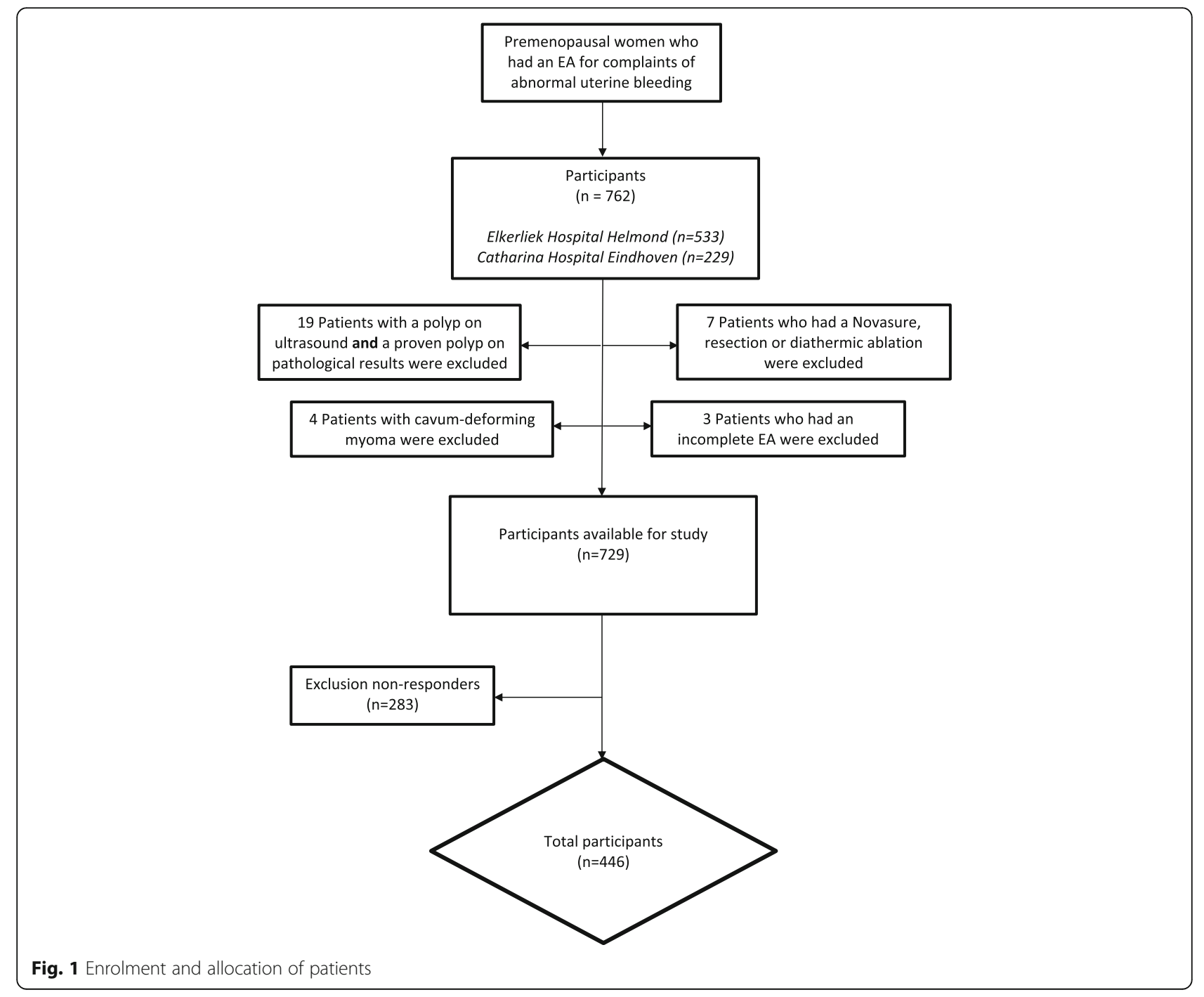


Table 1 Baseline patient characteristics $(N=446)$

\begin{tabular}{ll}
\hline Characteristic * & Value** \\
\hline Age (years) & $43.8 \pm 5.5$ \\
Body mass index $\left(\mathrm{kg} / \mathrm{m}^{2}\right)$ & $26.5 \pm 4.7$ \\
Dysmenorrhea & $57.4 \%$ \\
Follow-up time (days) & $1693.8 \pm 871.9$ \\
Duration of menstruation > 7 days $(n=429)$ & $39.4 \%$ \\
Intermittent or irregular bleeding & $61.0 \%$ \\
Length of the uterus $(\mathrm{cm})(n=402)$ & $9.1 \pm 1.1$ \\
Menorrhagia & $97.3 \%$ \\
Parity (no.) & $2.2 \pm 1.0$ \\
Previous caesarean section & $13.7 \%$ \\
Smoking $(n=445)$ & $21.6 \%$ \\
Sterilisation $(n=444)$ & $26.1 \%$ \\
Uterus position $(n=296)$ & \\
Anteverted & $72.3 \%$ \\
Retroverted & $23.6 \%$ \\
Midposition & $4.1 \%$ \\
\hline
\end{tabular}

${ }^{*} n=446$ unless otherwise mentioned

${ }^{* *}$ Mean \pm SD or a percentage

\section{Re-intervention model}

In the study group, $11.9 \% \quad(n=53)$ of the patients needed a surgical re-intervention within 2 years after EA. Univariate analyses showed that the following pre-operative variables were significantly associated with a higher probability of getting a surgical re-intervention within 2 years after EA $(p<.05)$ : age (OR 0.93, 95\% CI 0.89-0.98), dysmenorrhea (OR 2.83, 95\% CI 1.44-5.55), length of menstruation $>7$ days (OR 1.87, 95\% CI 1.04-3.37), parity $\geq 5$ (OR 5.84, 95\% CI 1.27-26.83), previous caesarean section (OR 2.98, 95\% CI 1.52-5.83) and pre-treatment (OR 0.40, 95\% CI 0.16-0.95) (Table 2). These pre-operative variables were included in the multivariate analyses.

In the final prediction model after multivariate analysis, the following pre-operative variables were significant: age (OR 0.95, 95\% CI 0.90-1.00), dysmenorrhea (OR 2.48, 95\% CI 1.21-5.07), length of menstruation $>7$ days (OR 2.05, 95\% CI 1.10-3.82), previous caesarean section (OR 2.21, 95\% CI 1.054.64) and parity $\geq 5$ (OR 7.63, 95\% CI 1.51-38.46) (Table 2). The C-index of the model was 0.71 .

No two-way interaction and multicollinearity between the variables was detected.

The shrinkage factor of 0.823 was used to correct the model.

Table 2 Pre-operative predictors of re-intervention after endometrial ablation

\begin{tabular}{|c|c|c|c|c|c|c|c|}
\hline \multirow[b]{2}{*}{ Variable } & \multicolumn{3}{|c|}{ Univariate analysis } & \multicolumn{3}{|c|}{ Multivariate analysis } & \multirow[b]{2}{*}{$\beta$} \\
\hline & Odds ratio & $95 \% \mathrm{Cl}$ & $p$ value & Odds ratio & $95 \% \mathrm{Cl}$ & $p$ value & \\
\hline Age (years) & 0.93 & $0.89-0.98$ & $<.01$ & 0.95 & $0.90-1.00$ & .06 & -0.052 \\
\hline Body mass index $\left(\mathrm{kg} / \mathrm{m}^{2}\right)$ & 0.99 & $0.93-1.05$ & .68 & & & & \\
\hline Dysmenorrhea & 2.83 & $1.44-5.55$ & $<.01$ & 2.48 & $1.21-5.07$ & .01 & 0.097 \\
\hline Duration of menstruation $>7$ days & 1.87 & $1.04-3.37$ & .04 & 2.05 & $1.10-3.82$ & .02 & 0.718 \\
\hline Intermittent or irregular bleeding & 1.56 & $0.84-2.89$ & .16 & & & & \\
\hline Menorrhagia & 0.67 & $0.14-3.12$ & .61 & & & & \\
\hline Myomas & 0.67 & $0.30-1.48$ & .33 & & & & \\
\hline Parity (no.) & 0.88 & $0.66-1.17$ & .38 & & & & \\
\hline Parity $\geq 5$ & 5.84 & $1.27-26.83$ & .02 & 7.63 & $1.51-38.46$ & .01 & 2.032 \\
\hline Pre-treatment* & 0.40 & $0.16-0.95$ & .04 & 0.49 & $0.20-1.22$ & .13 & - \\
\hline Previous caesarean section & 2.98 & $1.52-5.83$ & $<.01$ & 2.21 & $1.05-4.64$ & .04 & 0.794 \\
\hline Smoking & 1.36 & $0.70-2.62$ & .36 & & & & \\
\hline Sterilisation & 1.59 & $0.86-2.94$ & .14 & & & & \\
\hline \multicolumn{8}{|l|}{ Total endometrial thickness } \\
\hline Thin, $0-3 \mathrm{~mm}$ & 0.64 & $0.18-2.29$ & .49 & & & & \\
\hline Normal, 4-12 mm & 1.00 & - & - & & & & \\
\hline Thick, > $13 \mathrm{~mm}$ & 0.96 & $0.36-2.58$ & .93 & & & & \\
\hline Uterine cavity length of the uterus $(\mathrm{cm})$ & 1.16 & $0.88-1.54$ & .29 & & & & \\
\hline \multicolumn{8}{|l|}{ Uterus position } \\
\hline Anteverted & 1.00 & - & - & & & & \\
\hline Retroverted & 1.23 & $0.54-2.79$ & .63 & & & & \\
\hline Midposition & 2.77 & $0.70-10.96$ & .15 & & & & \\
\hline
\end{tabular}

*Any form of treatment (medicamentous or surgical) prior to the EA 
The final model after application of the shrinkage factor is as follows:

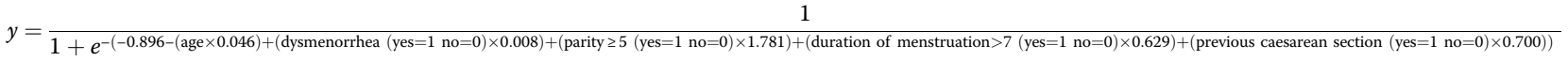

\section{Failure model}

In the study group, $35.8 \%(n=160)$ of the EA failed. Univariate analyses showed that the following pre-operative variables were significantly associated with a higher probability of failure of EA $(p<.05)$ : age (OR 0.93, 95\% CI 0.89-0.96), dysmenorrhea (OR 2.14, 95\% CI 1.42-3.23), menorrhagia (OR 0.27, 95\% CI $0.08-0.91$ ) and parity $\geq 5$ (OR 11.17 , 95\% CI $1.33-$ 93.60) (Table 3). The pre-operative variables with a $p$ value $p<.10$ were also included in the multivariate analyses; these were total endometrial thickness and pre-treatment.

In the final prediction model after multivariate analyses, the following pre-operative variables were significant: age (OR 0.93, 95\% CI 0.90-0.97), dysmenorrhea (OR 2.11, 95\% CI 1.37-3.26), menorrhagia (OR 0.21, 95\% CI 0.06-0.77) and parity $\geq 5$ (OR 11.19, 95\% CI 1.30-96.51) (Table 3). The C-index of the model was 0.68 .

No two-way interaction and multicollinearity between the variables was detected.

The shrinkage factor of 0.904 was used to correct the model.

The final model is as follows: there was no significant difference between the baseline data and the hysterectomy rates between the responders and the non-responders.

\section{Discussion \\ Main findings}

This study identified predictors for the outcome of EA as a treatment of abnormal uterine bleeding; this resulted in two prediction models, one for the probability of a surgical re-intervention within 2 years after EA (C-index 0.71$)$ and one for the probability of failure of EA (C-index 0.68).

\section{Explaining the models}

The significant factors seem to be in line with the previously published literature. [6, 11-15, 17-20]

An EA procedure at a younger age increases the risk of failure due to the longer interval until menopause. This increased time interval can also increase the risk of new complaints or re-intervention. In our model, age was used as a continuum, so the probability can be calculated more specifically based on the exact age of the individual patient.

$$
y=\frac{1}{\left.1+e^{-(3.485-(\text { age } \times 0.063)+(\text { dysmenorrhea }(\text { yes }=1 \text { no }=0) \times 0.677)+(\text { parity } \geq 5(\text { yes }=1 \text { no }=0) \times 2.183)-(\text { menorraghia }(\text { yes }=1 \text { no }=0) \times 1.400)}\right)}
$$

\section{Other results}

Our results showed that $82.6 \%(n=368)$ of patients were satisfied with the outcome of EA, and $86.8 \%(n=387)$ of patients would recommend EA to a friend.

Of the satisfied group, $14.6 \%(n=54)$ of patients had a new medical therapy or a surgical re-intervention. Furthermore, $32.7 \%(n=146)$ of the total population had an additional treatment after EA, varying from hormonal to surgical intervention.

The hysterectomy rate was $18.8 \%(n=83)$, and $61 \%(n$ $=51$ ) of this group had surgery within 2 years after EA. A total of $22.9 \%(n=102)$ of the study population had additional surgical treatment, $52 \%(n=53)$ of whom within 2 years after EA. Besides the number of smokers,
The significant factor of high parity $(\geq 5)$ is probably due to a larger multiparous uterine cavity, which is less congruent with an optimal fit of the ablation devices. However, we did not find a univariate significant difference in uterine cavity length.

Previous caesarean section as a significant negative risk factor can possibly be explained due to abnormal bleeding caused by uterine scar defects. It is possible that the device cannot make complete contact with the entire surface, especially in the inner part of the niche, leading to incomplete EA due to residual active endometrium [34]. Furthermore, in our models, pre-operative dysmenorrhea is associated with higher risk of failure and surgical re-intervention. 
Table 3 Pre-operative predictors of failure of endometrial ablation

\begin{tabular}{|c|c|c|c|c|c|c|c|}
\hline \multirow[b]{2}{*}{ Variable } & \multicolumn{3}{|c|}{ Univariate analysis } & \multicolumn{3}{|c|}{ Multivariate analysis } & \multirow[b]{2}{*}{$\beta$} \\
\hline & Odds ratio & $95 \% \mathrm{Cl}$ & $p$ value & Odds ratio & $95 \% \mathrm{Cl}$ & $p$ value & \\
\hline Age (years) & 0.93 & $0.89-0.96$ & $<.01$ & 0.93 & $0.90-0.97$ & $<.01$ & -0.070 \\
\hline Body mass index $\left(\mathrm{kg} / \mathrm{m}^{2}\right)$ & 0.99 & $0.95-1.03$ & .61 & & & & \\
\hline Dysmenorrhea & 2.14 & $1.42-3.23$ & $<.01$ & 2.11 & $1.37-3.26$ & $<.01$ & 0.749 \\
\hline Duration of menstruation $>7$ days & 1.26 & $0.84-1.89$ & .27 & & & & \\
\hline Intermittent or irregular bleeding & 1.22 & $0.82-1.83$ & .33 & & & & \\
\hline Menorrhagia & 0.27 & $0.08-0.91$ & .03 & 0.21 & $0.06-0.77$ & .02 & -1.544 \\
\hline Myomas & 0.92 & $0.56-1.49$ & .72 & & & & \\
\hline Parity (no.) & 0.88 & $0.73-1.07$ & .22 & & & & \\
\hline Parity $\geq 5$ & 11.17 & $1.33-93.60$ & .03 & 11.19 & $1.30-96.51$ & .03 & 2.415 \\
\hline Pre-treatment & 0.63 & $0.39-1.03$ & .07 & 0.74 & $0.37-1.47$ & .39 & - \\
\hline Previous caesarean section & 1.57 & $0.90-2.72$ & .11 & & & & \\
\hline Smoking & 0.73 & $0.45-1.18$ & .20 & & & & \\
\hline Sterilisation & 1.30 & $0.84-2.01$ & .24 & & & & \\
\hline \multicolumn{8}{|l|}{ TED } \\
\hline Thin, 0-3 mm & 0.94 & $0.47-1.85$ & .85 & 1.11 & $0.54-2.30$ & .78 & - \\
\hline Normal, 4-12 mm & 1.00 & - & - & & & & \\
\hline Thick, > $13 \mathrm{~mm}$ & 0.55 & $0.29-1.07$ & .08 & 0.56 & $0.27-1.16$ & .12 & - \\
\hline Uterine cavity length $(\mathrm{cm})$ & 1.07 & $0.89-1.28$ & .49 & & & & \\
\hline \multicolumn{8}{|l|}{ Uterus position } \\
\hline Anteverted & 1.00 & - & - & & & & \\
\hline Retroverted & 1.40 & $0.79-2.46$ & .25 & & & & \\
\hline Midposition & 1.51 & $0.46-4.95$ & .49 & & & & \\
\hline
\end{tabular}

*Any form of treatment (medicamentous or surgical) prior to the EA

Adenomyosis has been suggested to be a factor influencing the increased occurrence of (post-ablation) pelvic pain [35-38]. Pain is a subjective outcome measure. On the one hand, the level of pain can be explained by the coping mechanism of the patient; on the other hand, if a patient experiences many pre-operative complaints, the cause can be multifactorial (e.g. coping, dysmenorrhea, adenomyosis, endometriosis [37-41].

Performing ablation in patients with a certain extent of uterine pathology (fibroids, adenomyosis) can be seen as a risk for success of therapy [2, 34, 41, 42]. However, sensitivity and specificity of the diagnostic tools for determining these myometrial diseases are still low.As expected, thin endometrium is a positive predictor for ablation success due to the increased chance of complete penetration of heat during the EA. In multivariate analysis, however, this no longer was a significant factor.

Menorrhagia, defined as the subjective estimation of heavy bleeding (e.g. increased blood clots, overall bleeding quantity), is a patient characteristic that seems to fit the success profile for EA. This can be explained by the primary expected effect of EA: reduction of endometrial surface and subsequent bleeding.

Furthermore, we observed that pre-treatment leads to a univariate outcome of significantly higher risk of failure or re-intervention. Multiple treatments prior to EA can be an indication of the complexity of the underlying cause of the uterine disorder.

\section{Examples of using the models}

In clinical practice, the models can be used to estimate the risk of failure for individual patients. For instance, a 38-year-old patient, para 5, with a previous caesarean section, a menstrual duration of more than 7 days and complaints of dysmenorrhea and menorrhagia, has $93 \%$ chance of failure of EA and $62 \%$ chance of surgical re-intervention within 2 years after EA.

On the other hand, a 48-year-old woman, para 2, with no previous caesarean section, a menstrual duration shorter than 7 days and complaints of menorrhagia but no dysmenorrhea, has a chance of $28 \%$ failure of EA and $4 \%$ chance of surgical re-intervention within 2 years after EA (Table 4). 
Table 4 Clinical example

\begin{tabular}{lllll}
\hline Variable & Patient & Patient & Patient & Patient \\
& 1 & 2 & 3 & 4 \\
\hline Age (years) & 38 & 42 & 45 & 48 \\
Dysmenorrhea & Yes & No & Yes & No \\
Duration of menstruation $>7$ days & Yes & No & Yes & No \\
Menorrhagia & Yes & Yes & Yes & Yes \\
Parity $\geq 5$ & Yes & No & No & No \\
Previous caesarean section & Yes & No & Yes & No \\
Chance of failure of EA (\%) & $93 \%$ & $84 \%$ & $50 \%$ & $28 \%$ \\
Chance of getting a surgical re-intervention & $62 \%$ & $26 \%$ & $17 \%$ & $4 \%$ \\
$<2$ years after EA (\%) & & & & \\
\hline
\end{tabular}

\section{Other results}

In accordance with the literature, our results show that most re-interventions take place within 2 years after EA $[8,15,20-24]$.

Our study showed that $82.6 \%(n=368)$ of patients were satisfied with EA, and $86.8 \%(n=387)$ would recommend it to a friend. The discrepancy between the satisfaction and the percentage of re-interventions can be explained by the fact that many patients stated that they first wanted to try a minimally invasive therapy, instead of having a major surgery such as a hysterectomy. If the EA failed for them, they would still recommend the treatment to others, to possibly avoid a more invasive treatment.

As stated in previous literature, satisfaction is a difficult and subjective concept and therefore an outcome that is less reliable as an objective parameter for success [43-48].

\section{Strengths and limitations}

The two-centred aspect of the study ensures its representativeness. Furthermore, two researchers reviewed the charts, and if unclear answers were given, the patients were contacted by telephone to filter out wrong or misinterpreted data.

The models were developed with the data of 446 patients, who responded to our questionnaire. The hysterectomy rate in this group does not differ significantly from that of the non-responder group. The chance of selection bias therefore is minimal, although this cannot be completely ruled out.

The most important limitation of this retrospective study is the acquisition of data from patient charts with a non-validated questionnaire.

Besides the calculated probability of failure and re-intervention within 2 years, there still is a chance of having a re-intervention after this time; this cannot be calculated with the models.

An external validation of the prediction models is needed; this is currently being performed, using retrospective data of similar patient groups in two non-university teaching hospitals in the Netherlands. Furthermore, we are currently performing a study to investigate the impact of the models (and their corresponding individual percentages) in the decision of both the patients and doctors. The influence of costs of the treatment has not been added, although this may influence the choice of the patient or doctor. Therefore, this option has been added to a follow-up questionnaire of this study.

We are aware of the fact that some of the devices in the study are no longer used or have been updated; therefore, in the external validation, Novasure ${ }^{\bullet}$ and Thermachoice III $^{\oplus}$ will be added.

Previous research however showed that these techniques were similar effective $[13,21]$.

\section{Interpretation in light of other evidence}

When comparing existing literature concerning the success rates of EA, there seems to be some inconsistency in the importance of variables, especially when multivariate analyses were performed. Bongers et al. reported that dysmenorrhoea seems less important in predicting the outcome of EA in relation to other variables when performing multivariate analyses [9]. In contrast to this study, the multivariate prediction model produced by $\mathrm{El}$ Nashar et al. showed young age, high parity, history of sterilisation and pre-operative dysmenorrhea as significant prognostic factors for failure of EA. [6]

To illustrate the discrepancies in literature, a case-control study by Peeters et al. reported that the outcome is not predicted by age and sterilisation, but by pre-operative dysmenorrhea, submucous myomas and large-sized uteri. [19]

El Nashar et al. created a model to predict 'failure' of EA. Failure in this model was defined as bleeding or pain following EA, with the necessitating of having a hysterectomy or re-ablation. In this model, age as a continuum was not used [6]. Comparing outcomes of our study on re-intervention and complaints, we observed different significant variables predicting the two types of failure of EA. Therefore, we made two prediction models, so patients can be counselled for the chance of failure and for the risk of re-intervention. In this way, they can decide what is most important to them. The models still need external validation.

\section{Conclusion}

Proper patient selection is the key for failure or re-intervention of EA. Therefore, we propose two multivariate models to predict the chance of failure and surgical re-intervention within 2 years after EA. Due to the permanent character of EA, the increasing number of post-operative failure and re-interventions, these prediction models could be useful for both the doctor and patient and may contribute to the shared decision-making. 
Significant factors in these models are age, dysmenorrhea, duration of menstruation $>7$ days, menorrhagia, parity and previous caesarean section.

External validation of the models is being performed; furthermore, we are performing a study to see the impact of the models in the decision of both the patients and the doctor.

\section{Acknowledgements}

The authors thank the patients for completing the questionnaires and for consenting to participate in our study.

\section{Funding}

None

\section{Availability of data and materials}

The datasets generated and analysed during the current study are not publicly available due to privacy, but they are available from the corresponding author on a reasonable request.

\section{Authors' contributions}

KS contributed to the project development, data management, data analysis, and manuscript writing/editing. DM contributed to the project development, data collection, and manuscript editing. SH contributed to the data analysis and manuscript editing. TG contributed to the data collection and manuscript editing. SW contributed to the data collection and manuscript editing. BS contributed to the project development and manuscript editing. All authors read and approved the final manuscript.

\section{Ethics approval}

The ethical board in the Catharina hospital and in the Elkerliek hospital concluded that ethics approval was not necessary for this study.

\section{Consent for publication}

Not applicable

\section{Competing interests}

B.C. Schoot received fees from Medtronic on an hourly basis for lectures on hysteroscopic morcellation. The fees were donated to a foundation that promotes research in obstetrics and gynaecology. The remaining authors have no competing interests.

\section{Publisher's Note}

Springer Nature remains neutral with regard to jurisdictional claims in published maps and institutional affiliations.

\section{Author details}

${ }^{1}$ Department of Obstetrics and Gynaecology, Catharina Hospital, Michelangelolaan 2, 5623 Eindhoven, EJ, The Netherlands. 'Women's Clinic, Ghent University Hospital, Comeel Heymanslaan 10,9000 Ghent, Belgium. ${ }^{3}$ Department of Education and Research, Catharina Hospital, Michelangelolaan 2, 5623 Eindhoven, EJ, The Netherlands. ${ }^{4}$ Department of Obstetrics and Gynaecology, Elkerliek Hospital, Wesselmanlaan 25, 5707 Helmond, HA, The Netherlands.

Received: 18 December 2018 Accepted: 12 March 2019

Published online: 01 May 2019

\section{References}

1. Waddell G, Pelletier J, Desindes S, Anku-Bertholet C, Blouin S, Thibodeau D (2015) Effect of endometrial ablation on premenstrual symptoms. J Minim Invasive Gynecol 22(4):631-636. https://doi.org/10.1016/j.jmig.2015.01.023

2. Laberge P, Leyland N, Murji A, Fortin C, Martyn P, Vilos G et al (2015) Endometrial ablation in the management of abnormal uterine bleeding. J Obstet Gynaecol Canada. 2015;37(4):362-79

3. Bouzari Z, Yazdani S, Azimi S, Delavar MA (2014) Thermal balloon endometrial ablation in the treatment of heavy menstrual bleeding. Med Arch (Sarajevo, Bosnia Herzegovina) 68(6):411-413. https://doi.org/10.5455/ medarh.2014.68.411-413
4. Miller J, Troeger KA, Lenhart GM, Bonafede M, Basinski CM, Lukes AS (2015) Cost effectiveness of endometrial ablation with the NovaSure\&amp;reg; system versus other global ablation modalities and hysterectomy for treatment of abnormal uterine bleeding: US commercial and Medicaid payer perspectives. Int J Womens Health:59. https://doi.org/10.2147/IJWH. $\$ 75030$

5. Angioni S, Pontis A, Nappi L, et al. Endometrial ablation: first- vs. secondgeneration techniques. Minerva Ginecol 2016;68(2):143-153. http://www. ncbi.nlm.nih.gov/pubmed/26928420. Accessed 3 Dec 2018

6. El-Nashar SA, Hopkins MR, Creedon DJ et al (2009) Prediction of treatment outcomes after global endometrial ablation. Obstet Gynecol 113(1):97-106. https://doi.org/10.1097/AOG.0b013e31818f5a8d

7. Wishall KM, Price J, Pereira N, Butts SM, Della Badia CR (2014) Postablation risk factors for pain and subsequent hysterectomy. Obstet Gynecol 124(5): 904-910. https://doi.org/10.1097/AOG.0000000000000459

8. Thomassee MS, Curlin H, Yunker A, Anderson TL (2013) Predicting pelvic pain after endometrial ablation: which preoperative patient characteristics are associated? J Minim Invasive Gynecol 20(5):642-647. https://doi.org/10 1016/j.jmig.2013.04.006

9. Bongers MY, Mol BWJ, Brölmann HAM. Prognostic factors for the success of thermal balloon ablation in the treatment of menorrhagia. Obstet Gynecol 2002;99(6):1060-1066. http://www.ncbi.nlm.nih.gov/pubmed/12052600. Accessed 3 Dec 2018

10. Longinotti MK, Jacobson GF, Hung Y-Y, Learman LA (2008) Probability of hysterectomy after endometrial ablation. Obstet Gynecol 112(6):1214-1220. https://doi.org/10.1097/AOG.0b013e31818c1766

11. Shaamash AH, Sayed EH (2004) Prediction of successful menorrhagia treatment after thermal balloon endometrial ablation. J Obstet Gynaecol Res 30(3):210-216. https://doi.org/10.1111/j.1447-0756.2004.00189.x

12. Klebanoff J, Makai GE, Patel NR, Hoffman MK (2017) Incidence and predictors of failed second-generation endometrial ablation. Gynecol Surg 14(1):26. https://doi.org/10.1186/s10397-017-1030-4

13. Louie M, Wright K, Siedhoff MT (2018) The case against endometrial ablation for treatment of heavy menstrual bleeding. Curr Opin Obstet Gynecol. 30(4):287-292. https://doi.org/10.1097/GCO.0000000000000463

14. Bansi-Matharu L, Gurol-Urganci I, Mahmood T, Templeton A, van der Meulen J, Cromwell D (2013) Rates of subsequent surgery following endometrial ablation among English women with menorrhagia: populationbased cohort study. BJOG An Int J Obstet Gynaecol 120(12):1500-1507. https://doi.org/10.1111/1471-0528.12319

15. Shavell VI, Diamond MP, Senter JP, Kruger ML, Johns DA (2012) Hysterectomy subsequent to endometrial ablation. J Minim Invasive Gynecol 19(4):459-464. https://doi.org/10.1016/j.jmig.2012.03.013

16. Kalampokas E, McRobbie S, Payne F, Parkin DE (2017) Long-term incidence of hysterectomy following endometrial resection or endometrial ablation for heavy menstrual bleeding. Int J Gynecol Obstet 139(1):61-64. https://doi. org/10.1002/ijgo.12259

17. Cramer MS, Klebanoff JS, Hoffman MK (2018) Pain is an independent risk factor for failed global endometrial ablation. J Minim Invasive Gynecol 25(6): 1018-1023. https://doi.org/10.1016/j.jmig.2018.01.020

18. Bouzari Z, Yazdani S, Naeimi Rad M, Bijani A (2018) Is thermal balloon ablation in women with previous cesarean delivery successful? TURKISH J Med Sci 48(2):266-270. https://doi.org/10.3906/sag-1707-50

19. Peeters JAH, Penninx JPM, Mol BW, Bongers MY (2013) Prognostic factors for the success of endometrial ablation in the treatment of menorrhagia with special reference to previous cesarean section. Eur J Obstet Gynecol Reprod Biol 167(1):100-103. https://doi.org/10.1016/j. ejogrb.2012.11.009

20. Kreider SE, Starcher R, Hoppe J, Nelson K, Salas N (2013) Endometrial ablation: is tubal ligation a risk factor for hysterectomy. J Minim Invasive Gynecol 20(5):616-619. https://doi.org/10.1016/j.jmig.2013.03.011

21. Lethaby A, Penninx J, Hickey M, Garry R, Marjoribanks J (2013) Endometrial resection and ablation techniques for heavy menstrual bleeding. Cochrane Database Syst Rev (8):CD001501. https://doi.org/10.1002/14651858. CD001501.pub4

22. Sambrook AM, Bain C, Parkin DE, Cooper KG (2009) A randomised comparison of microwave endometrial ablation with transcervical resection of the endometrium: follow up at a minimum of 10 years. BJOG. 116(8): 1033-1037. https://doi.org/10.1111/j.1471-0528.2009.02201.x

23. Penninx JPM, Herman MC, Mol BW, Bongers MY (2011) Five-year follow-up after comparing bipolar endometrial ablation with hydrothermablation for 
menorrhagia. Obstet Gynecol 118(6):1287-1292. https://doi.org/10.1097/ AOG.0b013e318236f7ed

24. Herman MC, Penninx JPM, Mol BW, Bongers MY (2013) Ten-year follow-up of a randomised controlled trial comparing bipolar endometrial ablation with balloon ablation for heavy menstrual bleeding. BJOG. 120(8):966-970 https://doi.org/10.1111/1471-0528.12213

25. Steyerberg EW, Ejkkemans MJ, Habbema JD. Stepwise selection in small data sets: a simulation study of bias in logistic regression analysis. J Clin Epidemiol 1999;52(10):935-942. http://www.ncbinlm.nih.gov/pubmed/ 10513756. Accessed 3 Dec 2018

26. Steyerberg EW, Ejjkemans MJ, Harrell FE, Habbema JD. Prognostic modelling with logistic regression analysis: a comparison of selection and estimation methods in small data sets. Stat Med 2000;19(8):1059-1079. http://www. ncbinlm.nih.gov/pubmed/10790680. Accessed 3 Dec 2018

27. Hosmer DW, Lemeshow S. Applied logistic regression. 2nd editio. (ed. New York: John Wiley \& Sons; ed.).; 2000

28. C-statistics. Definition, Examples, Weighting and Significance: Statistics How To, www.statisticshowto.com/c-statistic/. Published 2018. Accessed 27 Mar, 2016

29. Collins GS, Reitsma JB, Altman DG, Moons KGM (2015) Transparent reporting of a multivariable prediction model for individual prognosis or diagnosis (TRIPOD): the TRIPOD statement. Br J Surg 102(3):148-158. https:// doi.org/10.1002/bjs.9736

30. Steyerberg EW, Harrell FE, Borsboom GJ, Eijkemans MJ, Vergouwe Y, Habbema JD. Internal validation of predictive models: efficiency of some procedures for logistic regression analysis. J Clin Epidemiol 2001;54(8):774781. http://www.ncbi.nlm.nih.gov/pubmed/11470385. Accessed 3 Dec 2018

31. Steyerberg EW (2018) Validation in prediction research: the waste by data splitting. J Clin Epidemiol 103:131-133. https://doi.org/10.1016/j.jclinepi. 2018.07.010

32. Steyerberg EW (2009) Clinical prediction models. A practical approach to development, validation and updating. Springer, New York

33. Bouwmeester W, Zuithoff NPA, Mallett S et al (2012) Reporting and methods in clinical prediction research: a systematic review. PLoS Med 9(5). https://doi.org/10.1371/journal.pmed.1001221

34. Moulder JK, Yunker A (2016) Endometrial ablation: considerations and complications. Curr Opin Obstet Gynecol 28(4):261-266. https://doi.org/10. 1097/GCO.0000000000000282

35. Kalish GM, Patel MD, Gunn MLD, Dubinsky TJ (2007) Computed tomographic and magnetic resonance features of gynecologic abnormalities in women presenting with acute or chronic abdominal pain Ultrasound Q 23(3):167-175. https://doi.org/10.1097/RUQ.0b013e31815202df

36. Orazov MR, Nosenko EN, Radzinsky VE, Khamoshina MB, Lebedeva MG, Sounov MA (2016) Proangiogenic features in chronic pelvic pain caused by adenomyosis. Gynecol Endocrinol 32(sup2):7-10. https://doi.org/10.1080/ 09513590.2016 .1232902

37. Radzinsky VE, Khamoshina MB, Nosenko EN et al (2016) Treatment strategies for pelvic pain associated with adenomyosis. Gynecol Endocrinol 32(sup2): 19-22. https://doi.org/10.1080/09513590.2016.1232673

38. Pontis A, D'Alterio MN, Pirarba S, de Angelis C, Tinelli R, Angioni S (2016) Adenomyosis: a systematic review of medical treatment. Gynecol Endocrinol 32(9):696-700. https://doi.org/10.1080/09513590.2016.1197200

39. Rogachov A, Cheng JC, Erpelding N, Hemington KS, Crawley AP, Davis KD (2016) Regional brain signal variability: a novel indicator of pain sensitivity and coping. Pain. 157(11):2483-2492. https://doi.org/10.1097/j.pain. 0000000000000665

40. Higgins NC, Bailey SJ, LaChapelle DL, Harman K, Hadjistavropoulos T (2015) Coping styles, pain expressiveness, and implicit theories of chronic pain. J Psychol 149(7):737-750. https://doi.org/10.1080/00223980.2014.977759

41. Busca A, Parra-Herran C (2016) The role of pathologic evaluation of endometrial ablation resections in predicting ablation failure and adenomyosis in hysterectomy. Pathol Res Pract 212(9):778-782. https://doi. org/10.1016/j.prp.2016.06.007

42. Loffer FD (2006) Endometrial ablation in patients with myomas. Curr Opin Obstet Gynecol. 18(4):391-393. https://doi.org/10.1097/01.gco.0000233932. 06060.aa

43. Al-Abri R, Al-Balushi A (2014) Patient satisfaction survey as a tool towards quality improvement. Oman Med J 29(1):3-7. https://doi.org/10.5001/omj. 2014.02

44. Urden LD. Patient satisfaction measurement: current issues and implications. Lippincotts Case Manag 7(5):194-200. http://www.ncbi.nlm.nih.gov/ pubmed/12394558. Accessed December 3, 2018
45. Yellen E, Davis GC, Ricard R. The measurement of patient satisfaction. J Nurs Care Qual 2002;16(4):23-29. http://www.ncbi.nlm.nih.gov/pubmed/ 12125901. Accessed December 3, 2018

46. Bjertnaes OA, Sjetne IS, Iversen HH (2012) Overall patient satisfaction with hospitals: effects of patient-reported experiences and fulfilment of expectations. BMJ Qual Saf 21(1):39-46. https://doi.org/10.1136/bmjqs-2011000137

47. Rama Mohan DD, Kanagaluru Sai Kumar D. A study on the satisfaction of patients with reference to hospital services. Vol 1.; 2011. http://www. zenithresearch.org.in/images/stories/pdf/2011/Dec/ZIBEMR/2_ZIBEMR_ VOL1_ISSUE3.pdf. Accessed 3 Dec 2018.

48. Kilbourne WE, Duffy JA, Duffy M, Giarchi G (2004) The applicability of SERVQUAL in cross-national measurements of health-care quality. J Serv Mark 18(7):524-533. https://doi.org/10.1108/08876040410561857

\section{Submit your manuscript to a SpringerOpen ${ }^{\circ}$ journal and benefit from:}

- Convenient online submission

- Rigorous peer review

- Open access: articles freely available online

- High visibility within the field

- Retaining the copyright to your article

Submit your next manuscript at $\boldsymbol{\nabla}$ springeropen.com 